\title{
Generative Design in the Transmission System of a Skateboard
}

\author{
Mikel Iturrate ${ }^{1(\otimes)}$, Xabier Amezua $^{2}$, Xabier Garikano $^{2}$, Jose Antonio Oriozabala $^{2}$, \\ Iñaki Martin $^{3}$, and Eneko Solaberrieta ${ }^{3}$ \\ ${ }^{1}$ Department of Business Management, Gipuzkoa Faculty of Engineering, University of the \\ Basque Country UPV/EHU, Donostia, Spain \\ mikel.iturrate@ehu.eus \\ 2 Department of Graphic Design and Engineering Projects, Gipuzkoa Faculty of Engineering, \\ University of the Basque Country UPV/EHU, Donostia, Spain \\ 3 Department of Graphic Design and Engineering Projects, Gipuzkoa Faculty of Engineering, \\ University of the Basque Country UPV/EHU, Eibara, Spain
}

\begin{abstract}
Generative design (GD) is a new way of designing products that respond to the current characteristics of the 4.0 industry era. It allows the customization of designs and helps to minimize process times and material quantities. In the case study, two parts of the transmission system of a skateboard have been designed using GD of Solid Edge ST10. The design has been customized for $67 \mathrm{~kg}$ users who will use the skateboard for riding and not for jumping or doing tricks. On the other hand, the aim was to minimize the weight and the use of material for its manufacture. Once the initial solid is defined, the software generates specific designs for different levels of mass reduction or product quality. An axle with a mass reduction of $70 \%$ from the initial solid and a base with reduction of $60 \%$ have been proposed. The GD more than an alternative is a requirement to respond to the demands of the 4.0 industry in which customization and cost reduction are one of the fundamental pillars. This type of design, at the same time, forces to adapt the manufacturing processes so that it is necessary to manufacture in additive manufacturing (AM) machines.
\end{abstract}

Keywords: Generative design · Additive manufacturing · 4.0 Industry · Customisation

\section{Introduction}

The concept of industry 4.0 refers to a new way of organizing productive resources. The aim is to set up smart factories capable of offering greater adaptability to production needs and processes and making the allocation of resources more efficient, paving the way for this new industrial revolution [1]. It will join technological achievements made in recent years with the modern use of information technologies [2, 3]. Industry 4.0 seeks to guarantee the flexibility and efficiency of production but at the same time facilitating the strategy known as mass customization (MC) that focuses on satisfying the individual requirements of each client $[1,4]$.

(C) The Author(s) 2021

L. Roucoules et al. (Eds.): JCM 2020, LNME, pp. 169-174, 2021.

https://doi.org/10.1007/978-3-030-70566-4_27 
Studies show that approximately $80 \%$ of design time is spent on routine tasks with little or no added value [5]. However, current design tools such as CAx tools (Computer Aided Technologies) make possible rapid design with automated tools and define technical specifications of a product without the participation of a design engineer [2]. These technologies are penetrating the manufacturing industry, making it intelligent and adaptable to current market requirements of customization, better product quality and shorter time to market [6, 7]. Topology optimization has also emerged as the mayor light weighting strategy in order to greater efficiency or lower energy consumption, best exploiting the design freedoms offered by generative design (GD) [8]. GDs main goal is to optimize the distribution of material within boundaries and respecting the requirements of loads or functional surfaces [9]. This new way of designing has coexisted for a while but it has been better known in non-industrial fields [10].

Using GD engineers can analyse the different options presented in a more dynamic way and select the one that best responds to the requirements. In addition, it offers solutions that would not be possible to design with conventional design tools. However, due to the shapes of these designs, it is not possible to manufacture the parts entirely using conventional technologies and additive manufacturing (AM) is required. However, with AM the surfaces of the parts are currently of high roughness and have imprecise finishes making the use of conventional technologies still necessary.

AM allows the manufacture of customized objects with sophisticated designs and in new materials. This technology has undergone an important evolution, improving aspects such as the precision or the production speed in addition to a considerable decrease in costs [11]. Thus, in some cases AM has already replaced conventional manufacturing techniques, although there are still reasonable doubts regarding its use in mass production [12].

The present work aims to show the possibilities offered by GD. For this purpose, two pieces of a skating board have been designed using this technology and the results have been compared with a conventional design of these same pieces.

\section{Materials and Methods}

GD has been used (Solid Edge ST10) to design two pieces that participate in the rolling system of a skateboard. The rolling system is a set divided into different parts: wheels, axle, intermediate joints, the base and different elements of union (Fig. 1A). Obviously, it is not suitable to apply GD in all these parts. Therefore, GD has only been applied to design the axle (Fig. 1B) and the base (Fig. 1C).

First of all, the boundaries are defined by designing the solid of each part.
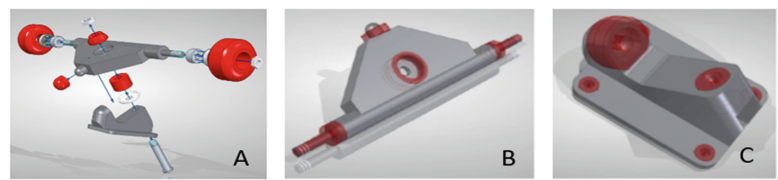

Fig. 1. The rolling system (A) and the solids of the axle (B) and the base (C) Functional surfaces in red in $\mathrm{B}$ and $\mathrm{C}$. 
It must be defined the main dimensions of the parts and the functional surfaces, which in the case of the axle, are the wheel seats and the hole (In red in Fig. 1B). In the case of the base, the functional surfaces are the joint seats and the surfaces in contact with the shaft (In red in Fig. 1C).

After defining the solids and their functional surfaces, the next step will be the stress calculation. The skateboard is designed for $67 \mathrm{~kg}$ users that use it for displacements and not for jumping or do tricks. Even so in the design will be considered that the skateboard can be used by a person of $80 \mathrm{~kg}$ and it was applied a safety coefficient of 1.2. The material chosen for fabrication in both, the axle and the base is $580510 \mathrm{NiCr} 5$ 4 steel alloy (Brinell Hardnesss 140-170, Elastic (Young's, Tensile) Modulus 190 GPa, Poisson's Ratio 0.29, Shear Modulus 73 GPa, Tensile Strength: Ultimate (UTS) 460 to $1180 \mathrm{Mpa})$.

Several tests have been carried out with each part without altering the restrictions in terms of stress and material on functional surfaces but varying the quality and the percentage of weight reduction from $20 \%$ to $70 \%$.

\section{Results}

Table 1 show different design solutions for both parts of the skateboard (axle and base) when applying different mass reduction. In addition, the figures in the tables show the critical surfaces represented in colour maps. Blue areas represent non-critical surfaces while green, yellow or red areas represent critical ones.

Table 1. Different axle and base design results by applying varying degrees of mass reduction.

\begin{tabular}{|c|c|c|}
\hline REDUCTION & PROPOSED AXLE & PROPOSED BASE \\
\hline $40 \%$ & & \\
\hline $60 \%$ & & \\
\hline $70 \%$ & & \\
\hline
\end{tabular}

In the case of the axle, it is possible the design that reaches the $70 \%$ of mass reduction. The mass has been reduced from $0.974 \mathrm{~kg}$ of the initial solid to $0.292 \mathrm{~kg}$ of the proposed solution. Its' admissible maximum stress is $246.328 \mathrm{MPa}$. However, in the case of the base, the proposed design for a $70 \%$ mass reduction is clearly unsatisfying. The base 
has been splitted in two parts becoming useless. Thus, the best solution is the one that reaches the $60 \%$ of mass reduction. The base mass has been reduced from $0.391 \mathrm{~kg}$ to $0.156 \mathrm{~kg}$. The maximum admissible stress is also $246.328 \mathrm{MPa}$.

Besides designing the two parts, 2D plans of the axle and the base have been drawn up in order to define the functional surfaces. To machine these functional surfaces, both parts must be placed on specifically designed tooling that also must have been designed and represented in $2 \mathrm{D}$ plans.

\section{Discussion}

Results section show shapes of the designed parts far from simple geometries. In addition, GD help reducing the participation of design engineers by automatizing, contributing in some purposes of industry 4.0 such as the reduction of designing processes times [2] or minimising time spent in routine tasks [5]. Besides, GD make it possible to easily design personalized products responding to MC requirements [1, 4, 6, 7].

Topology optimization has also contributed improving efficiency by reducing both pieces mass [8]. Comparing the originally designed solids with the result, a large material removal is observed. It is also noticeable how the program respects the requirement to not remove material in areas where removal has been restricted. These areas are represented in dark blue, showing that they are under minimal stress.

On the other hand, these shapes can be restrictive because they cannot be manufactured using conventional technologies, and it could condition the implementation of GD. AM enable the manufacture of these shapes, but on the other hand, have their limitations, especially in terms of surface finishing or mass production. Consequently, some functional surfaces and threads must be necessarily mechanised in traditional machine tools.

\section{Conclusions}

GD not only offers a different alternative to traditional design methods, also facilitates product customization, reduces design time and optimizes the amount of material required to manufacture. However, GD does not imply the disappearance of 2D dimensional drawings since all functional surfaces must continue to be manufactured according to traditional methods and these require 2D drawings. Instead, it significantly simplifies the creation of these drawings.

Parts designed using GD will need 3D printing machines to be manufactured. These machines have the advantage of versatility in terms of manufacturing complex shapes or better use of materials, but are limited in terms of obtaining good surface finishes or manufacturing large quantities.

In the case study, it was possible to design two parts of a skateboard using GD. These pieces have a certain level of customization due to the fact that they have been designed for a certain user profile. In addition, the material and weight of the pieces have been minimized by 60 to $70 \%$. 
Acknowledgements. The authors of this paper thank the Faculty of Engineering Gipuzkoa for locating the DEHI laboratory in their facilities, and the Country Council of Gipuzkoa (Grant $\mathrm{n}^{\circ}$ 70/19) and MINECO Ministry of Economy and Competitiveness (grant number PID2019108975RA-I00) for financing this project.

\section{References}

1. Pasetti Monizza, G., Bendetti, C., Matt, D.T.: Parametric and generative design techniques in mass-production environments as effective enablers of industry 4.0 approaches in the Building Industry. Autom. Constr. 92, 270-285 (2018)

2. Zawadzki, P., Zywicki, K.: Smart product design and production control for effective mass customization in the industry 4.0 concept. Manag. Prod. Eng. Rev. 7(3), 105-112 (2016)

3. Lee, J., Bagheri, B., Kao, H.A.: A cyber-physical systems architecture for Industry 4.0-based manufacturing systems. Manuf. Lett. 3, 18-23 (2015)

4. Shrouf, F., Ordieres, J., Miragliotta, G.: Smart factories in Industry 4.0: a review of the concept and of energy management approached in production based on the Internet of things paradigm. In: IEEE International Conference on Industrial Engineering and Engineering Management, vol. 2015, pp. 697-701, January 2014

5. Stokes, M.: Managing Engineering Knowledge: MOKA: Methodology for Knowledge Based Engineering Applications. Strategy, p. 257 (2001)

6. John, J.F.R., Rittinghouse, W.: Cloud Computing Implementation, Management, and Security (2010)

7. Zheng, P., et al.: Smart manufacturing systems for Industry 4.0: conceptual framework, scenarios, and future perspectives. Front. Mech. Eng. 13(2), 137-150 (2018)

8. Plocher, J., Panesar, A.: Review on design and structural optimisation in additive manufacturing: towards next-generation lightweight structures. Mater. Design 183, 108164 (2019)

9. Tyflopoulos, E., Flem, D.T., Steinert, M., Olsen, A.: State of the art of generative design and topology optimization and potential research needs. Proc. Nord. Des. Era Digit. Nord. 2018, $1-5(2018)$

10. Jana, G., Miroslav, V., Ladislav, G.: Surface interpolation and procedure used in the generative engineering design of surface-based automotive components. Int. J. Veh. Des. 77(4), 211-226 (2018)

11. Stock, T., Seliger, G.: Opportunities of sustainable manufacturing in industry 4.0. Procedia CIRP 40, 536-541 (2016)

12. Dilberoglu, U.M., Gharehpapagh, B., Yaman, U., Dolen, M.: The role of additive manufacturing in the era of industry 4.0. Procedia Manuf. 11, 545-554 (2017) 
Open Access This chapter is licensed under the terms of the Creative Commons Attribution 4.0 International License (http://creativecommons.org/licenses/by/4.0/), which permits use, sharing, adaptation, distribution and reproduction in any medium or format, as long as you give appropriate credit to the original author(s) and the source, provide a link to the Creative Commons license and indicate if changes were made.

The images or other third party material in this chapter are included in the chapter's Creative Commons license, unless indicated otherwise in a credit line to the material. If material is not included in the chapter's Creative Commons license and your intended use is not permitted by statutory regulation or exceeds the permitted use, you will need to obtain permission directly from the copyright holder.

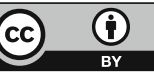

